\title{
Consent to DNA collection in epidemiological studies: findings from the Whitehall II cohort and the English Longitudinal Study of Ageing
}

\author{
Susanne F. Meisel, MSc, Aparna Shankar, PhD², Mika Kivimaki, $\mathrm{PhD}^{2}$ and Jane Wardle, $\mathrm{PhD}^{1}$
}

Purpose: Epidemiological studies increasingly include DNA sampling in their protocols, but participation may vary by demographic, psychological, or health characteristics. This analysis explored sociodemographic (age, gender, religion, and education), health-related, and psychological predictors of participation in genetic data collection in two large epidemiological studies: the Whitehall II cohort and the English Longitudinal Study of Ageing. DNA consent in both studies was not obtained on initial enrollment, but after long-standing participation in the study.

Methods: Study participants who accepted or declined DNA sampling were compared.

Results: Very few participants declined DNA sampling; $1.6 \%$ in Whitehall II and 1.0\% in English Longitudinal Study of Ageing. In both cohorts, participants who declined were more likely to be

\section{INTRODUCTION}

As the genetic component for many diseases is increasingly understood, integration of genetic testing into general medicine is becoming mainstream, ${ }^{1}$ and "personalizing" healthcare based on genomic information is seen as a major goal for the future. ${ }^{2,3}$ Defining and elucidating the multifaceted genetic interactions that underpin common complex diseases requires large-scale genetic studies with data from thousands of individuals. Biobanks, which are set up to store large collections of biological material for long periods of time, are the foundation for these studies. They rely on the voluntary participation of the general public, and unwillingness to contribute could compromise the success of some genetic projects. Hypothetical studies, conducted before some of the Biobanks were set up anticipated rates of participation as high as $70 \%, 4,5$ and subsequent findings suggest that the general public are willing to contribute DNA samples to Biobanks despite some concerns about issues such as confidentiality ${ }^{6}$ and in the absence of any immediate personal gains. However, formal reports on participation rates are rare. The Icelandic company DeCODE reports more than 140,000 participants on their website (www.decode.com), which is approximately half of Iceland's total population. UK Biobank recently achieved their goal of collecting DNA from 500,000 volunteers (www.ukbiobank.ac.uk), and refusal of DNA storage was rare in the Swedish population. ${ }^{7}$ A study of the correlates of female, nonwhite, and involved in religious activities; although only the ethnic effect consistently survived multivariate analyses. Decliners also felt less in control of events in their lives than those who consented, and this remained significant in multivariate analysis in the English Longitudinal Study of Ageing sample.

Conclusion: Consent to DNA sampling was very high in two established UK cohort studies. Differences between the subset of the population unwilling to provide DNA samples and those who consented were modest, although this may be due to the highly selected populations in these cohorts. However, our findings suggest that a greater proportion of decliners would create an important source of selection bias.

Genet Med 2012:14(2):201-206

Key Words: cohort; consent; DNA; ELSA; genetic testing; Whitehall II

intended participation before development of a biobank in the United States found that those who intended to participate were more likely to be male, older, nonethnic minority, and of higher socioeconomic status (SES), although only gender remained a significant predictor in a multivariate model. ${ }^{4}$

Many large-scale epidemiological studies also incorporate collection and storage of genetic data, but few have examined predictors of participation. Giving DNA in epidemiological studies is similar to the biobank situation in that it has no immediate benefit for the individual. The major difference is that in epidemiological studies, individuals may already have disclosed personal and medical information and are usually followed up closely for a number of years. Furthermore, they are already selected from the general population as willing to participate in medical research, and they may, therefore, be more likely to participate in a genomic component.

One of the few studies to investigate participation in DNA storage used quantitative and qualitative methods as part of the longitudinal Population-based Study of Mental Health in the Stockholm County (PART). ${ }^{8}$ Participants who declined DNA sampling were sent a questionnaire containing seven reasons for refusal (e.g., lack of personal relevance and lack of time). Out of those who agreed with any of those reasons, a subsample was selected for more detailed interviews. The main reason endorsed for refusal was lack of personal relevance, although 
this was not associated with age, gender, or education. However, concern that the DNA might be used for reasons other than those initially specified was significantly more endorsed by men, younger people, and those who were educated above elementary school level; groups who were expected to have higher levels of participation. These findings are not consistent with the results described earlier on correlates of intended participation in biobanks, ${ }^{4}$ and we are not aware of any other studies looking at predictors of participation in genetic data collection in epidemiological surveys.

The aim of the analyses was to explore sociodemographic characteristics, health status, and psychological factors as predictors of participation in genetic data collection in two large epidemiological studies: the Whitehall II cohort and the English Longitudinal Study of Ageing (ELSA). Although previous results have been mixed, ${ }^{4,8}$ there are suggestions that being male, higher SES, and from a nonethnic minority background are associated with participation. On the basis of evidence on determinants of participation in research studies in general, ${ }^{9}$ we also hypothesized that people who were depressed, had poorer health, or perceived less control over their lives would be more likely to decline testing.

\section{MATERIALS AND METHODS}

\section{Participants}

The Whitehall II cohort. The Whitehall II cohort was recruited between 1985 and 1988 and consists of British civil servants from 20 departments. Those aged $35-55$ years at the time of recruitment were invited into the study. The original participation rate was $73 \%$ (10,308 participants). Baseline data collection consisted of a physical examination, a blood sample, and administration of questionnaires. Participants have been followed up with a clinic visit every 5 years, and additional questionnaire data are collected in between follow-up periods. In Phase 3 of data collection (1991-1994), DNA sampling derived from the blood sample was included. For those unable to attend the clinic, a nurse visit was added in Phase 7 (2003-2004) to minimize attrition rates.

This analysis focuses on Phase 7 of data collection and includes 6870 (67\%) of the participants who began the study. Participant dropout occurred mainly in the first follow-up phase; attrition in later phases was predominantly due to participant illness or death. ${ }^{10}$ Mean age at Phase 7 was 61.2 years (SD: 5.99 years), and $70 \%$ of the sample were men, which reflected the target population.

The ELSA cohort. ELSA is a panel study of adults aged 50 years and older living in England. ELSA participants were selected from respondents to the Health Survey for England (an annual, nationally representative cross-sectional household survey) in 1998, 1999, or 2001 who were born before February 30, 1952 (i.e., who would be aged 50 years or older at the start of fieldwork for ELSA Wave 1 in 2002). Participants have been followed up every 2 years, with nurse visits including blood sample analysis carried out in alternate waves.
This analysis included participants from Wave 2 of ELSA (2004), which was the first wave in which a nurse visit was carried out. The main reason for nonparticipation in ELSA was refusal.

Obtaining consent. In Whitehall II, consent for blood sampling for physiological measures and DNA collection was obtained separately in person by a trained researcher. Participants consented by having to "opt-in" and agreed separately to each physiological measure (i.e., blood pressure, weight, and cholesterol testing). All participants had the option to consent to DNA analysis even if they declined blood testing at this phase of data collection, as bloods were stored from previous data collection phases. There were no formal exclusion criteria for blood collection, and all but 28 participants $(0.03 \%)$ consented to blood sampling for physiological measures.

In ELSA, participants completed an interview in person $(N=8688)$, during which they were offered a nurse visit to draw blood and take physiological measures. Consent for the nurse visit was obtained at the end of the interview and $88 \%$ of eligible participants consented. As in Whitehall II, during the nurse visit, participants consented separately for each component. Blood samples were not collected from participants with a clotting or bleeding disorder, who were on anticoagulants, or had ever had a fit. In contrast to Whitehall II, only participants who agreed to blood drawing were asked whether they would be willing for their sample to be stored for future analysis, and only participants who agreed to this were asked whether they were willing to consent for genetic analysis of the sample. More than $80 \%$ of the eligible population provided a blood sample. Those who consented to blood drawing were younger, of higher SES, in better health, and more physically active than those who declined. ${ }^{11}$ This analysis included 6618 participants $(46.3 \%$ men, mean age: 66.9 years) who had provided a blood sample and consented for it to be stored for future analysis.

Further details on both study cohorts and sampling methods have been published elsewhere. ${ }^{10-14}$ Participants in both cohorts gave full informed consent for participation, and ethical approval was obtained from the relevant Ethics committees.

\section{Measures}

Demographics. In both samples, demographic information included age, gender, marital status, and ethnicity. For the purpose of this analysis, marital status was coded as married/living with a partner versus not, and ethnicity was coded as white versus nonwhite. Participants were also asked whether they were involved in religious activities (yes/no).

The reason for dichotomizing ethnicity was the homogenous distribution in both samples, with few participants selfidentifying as nonwhite and hence extremely few in any specific ethnic group. In Wave 1 of ELSA, $96.5 \%$ of men and $97.7 \%$ of women were white; $1.7 \%$ of men and $0.9 \%$ of women were Asian; and same percentage of women was black. The remaining $0.8 \%$ of men and $0.5 \%$ of women were of other ethnicities. In the following waves, ethnicity remained dichotomized. In Whitehall II, 
$89.5 \%$ of men and $82.6 \%$ of women were White Europeans; $5.2 \%$ and $6.5 \%$ were Asian, $2.0 \%$ and $6.4 \%$ were Afro-Caribbean; and $3.3 \%$ and $4.5 \%$ had other ethnic origin, or it was unknown.

Socioeconomic status. Wealth has been shown to better capture economic resources available to older adults and may be a better measure of SES for a study of this age range than income, occupation, or education. ${ }^{15-17}$ In Whitehall II, wealth was determined by the self-reported "amount of money the respondent would have if she cashed in all household assets and paid off all debts." For the purpose of this analysis, four categories were formed by combining the top and bottom two categories, and thereafter, the variable was dichotomized into the lowest category versus the other three categories. Quintiles of total wealth, not including money obtained via pension, were used as a measure of SES in ELSA. Wealth was calculated as net of debt and includes the value of any home and other property (less mortgage), financial assets covering all types of savings available in England, and the value of any business assets or artifacts such as artwork and jewelry. ${ }^{18}$ The variable was then dichotomized into "lowest quintile" versus the other categories to allow for comparison with Whitehall II.

Self-reported health. Self-reported health was assessed with the statement "my health is excellent," which was rated on a 4-point Likert scale (often, sometimes, rarely, and never) from the Medical Outcomes Survey 36-item short-form health survey in the Whitehall study ${ }^{19}$ and with "my health is__ " (with options of excellent, very good, good, fair, or poor) in ELSA. For this analysis, responses were dichotomized into "often" (Whitehall) and "excellent" (ELSA) versus all other responses.

Anxiety and depression. Participants in both samples were asked about any diagnosis of anxiety or depression. In addition, symptoms of anxiety/depression were assessed with the self-administered 30-item General Health Questionnaire ${ }^{20}$ in Whitehall II and the 8-item version of the Centre for Epidemiologic Studies Depression Scale ${ }^{21}$ in ELSA.

Chronic pain. In ELSA, participants were asked whether they were often troubled by pain (yes/no). In Whitehall II, chronic pain was assessed with the pain subscale of the short form health survey, a standardized measure to assess quality of life. ${ }^{19}$ To be comparable with ELSA, pain subscale scores were dichotomized into low versus high pain. Lower scores indicate more pain.

Perceived control of life. In both samples, participants were asked whether they felt that "what happens to me is out of my control" with response options being "often," "sometimes," "rarely," "never," which was derived from the CASP-19, which is a standardized measure of quality of life with established reliability and validity for use in older adults. ${ }^{22}$ Assessed are four domains of quality of life, control, autonomy, self-realization and pleasure, whose first letters are used to build the acronym CASP.

\section{Statistical analyses}

$t$ tests were used to compare means for continuous variables and Fisher's exact test for dichotomous outcomes. Subsequent binary regression included education, ethnicity, and involvement in religious activity as predictor variables for consenting to DNA collection. All analyses were carried out using SPSS v.17. Analyses for the ELSA sample were weighted for nonresponse for blood sampling. Whitehall II does not provide weights to correct for nonresponse as it is not a populationbased study.

\section{RESULTS}

Very few participants declined to give a DNA sample. In the Whitehall II cohort, 134 participants declined DNA collection out of a sample of 6870 (1.6\%). In the ELSA cohort, 66 participants declined to provide a DNA sample out of 6618 (1.0\%; weighted). Table 1 lists descriptive results in terms of differences between those who declined and accepted DNA sampling. Decliners were significantly more likely to be female than acceptors in Whitehall II ( $42.5 \%$ in decliners vs. $29.2 \%$ in acceptors, $P<0.001$ ), with a trend in the same direction in ELSA ( $65.6 \%$ vs. $53.7 \%, P=0.071$ ). There were no age differences, but neither group included young participants. In Whitehall II, decliners were less likely to have any educational qualifications ( $11.0 \%$ vs. $20.7 \%, P=0.01$ ), which was not the case in ELSA (39.3\% vs. $40.9 \%)$. Wealth, on the other hand, was not a significant predictor of DNA consent in either sample $(P=0.192$ in ELSA; $P=0.633$ in Whitehall II). In both samples, decliners were less likely to be married, but the difference was not statistically significant. Decliners were significantly more likely to be from ethnic minorities in both samples $(8.2 \%$ vs. $2.2 \%$ in ELSA, $P=0.012 ; 22.4 \%$ vs. $7.9 \%$ in Whitehall II, $P<0.001$ ). Involvement in religious activities was more common in decliners in Whitehall II (55.9\% vs. $44.4 \%, P=0.015)$ and in the same direction although not statistically significant in ELSA $(26.9 \%$ vs. $22.6 \%, P=0.504)$.

In the health domain, fewer decliners were in good health in Whitehall II (6.6\% vs. $14.8 \%, P=0.009)$. In ELSA, the direction was the same, although differences were not significant $(6.7 \%$ vs. $12.1 \%, P=0.236)$. There was no difference in either sample with respect to depression ( $P=0.058$ in Whitehall II). Decliners in Whitehall II were more likely to report pain $(35.8 \%$ vs. $25.0 \%$, $P=0.010)$, but in ELSA, no such difference was observed (38.2\% vs. $39.3 \%, P=0.895)$. In ELSA, more decliners felt that they did not have control over events that happen to them (15.1\% vs. $5.5 \%, P=0.009)$, whereas no differences were observed in Whitehall II ( $2.7 \%$ vs. $4.2 \%, P=0.254)$.

Results for the multivariate regression analysis for the Whitehall II cohort are presented in Table 2. Ethnic minority status, but not education or religious activity, remained associated with declining DNA collection $(P=0.001)$. Wealth was not associated with consenting, but age showed a trend toward significance $(P=0.099)$, with those who were older being more likely to decline DNA collection. In the psychological and health domains, perceived control over life events, self-reported 
Table 1 Characteristics of consenters and decliners of genetic testing in two older adult cohorts Demographics

ELSA cohort

Whitehall cohort

\begin{tabular}{|c|c|c|c|c|c|c|}
\hline & & & & \\
\hline & $\begin{array}{c}\text { Consenters } \\
(n=6,552), 98.8 \%\end{array}$ & $\begin{array}{c}\text { Decliners } \\
(n=66), 1.2 \%\end{array}$ & $\begin{array}{l}P \text { (Fisher's exact } \\
\text { test or } t \text { test) }\end{array}$ & $\begin{array}{c}\text { Consenters } \\
(n=6,736), 98.4 \%\end{array}$ & $\begin{array}{c}\text { Decliners } \\
(n=134), 1.6 \%\end{array}$ & $\begin{array}{l}P \text { (Fisher's exact } \\
\text { test or } t \text { test) }\end{array}$ \\
\hline Sex (\% male) & 46.3 & 34.4 & 0.071 & 70.8 & 57.5 & 0.001 \\
\hline Ethnicity (\% nonwhite) & 2.2 & 8.2 & 0.012 & 7.9 & 22.4 & 0.001 \\
\hline Age, mean (SD) & $66.7(10.5)$ & $68.1(12.7)$ & 0.441 & $61.2(6.3)$ & $62.2(5.9)$ & 0.092 \\
\hline $\begin{array}{l}\text { Marital status (\% Married/ } \\
\text { cohabiting) }\end{array}$ & 68.6 & 58.3 & 0.094 & 75.6 & 69.5 & 0.123 \\
\hline Intermediate & 48.0 & 52.5 & & 53.5 & 68.3 & \\
\hline No qualifications & 40.9 & 39.3 & 0.680 & 11.0 & 20.7 & 0.011 \\
\hline $\begin{array}{l}\text { Wealth (ELSA: \% in lowest } \\
\text { quintile and Whitehall: } \\
\% \text { assets up to } f 40 \mathrm{k} \text { ) }\end{array}$ & 20.1 & 27.1 & 0.192 & 8.1 & 9.0 & 0.633 \\
\hline Chronic pain ( $\%$ yes, \% high) & 38.2 & 39.3 & 0.895 & 25.0 & 35.8 & 0.010 \\
\hline Depression (mean score) & $1.60(1.98)$ & $1.45(1.56)$ & 0.441 & $0.96(1.81)$ & $1.28(1.88)$ & 0.058 \\
\hline $\begin{array}{l}\text { Self-reported control over life } \\
\text { events (\% often) }\end{array}$ & 5.5 & 15.1 & 0.009 & 2.7 & 4.2 & 0.254 \\
\hline
\end{tabular}

ELSA, English Longitudinal Study of Ageing.

aThis was measured in Whitehall with "My health is excellent" (often/sometimes/rarely/never) and in ELSA with "My health is __" (excellent/very good/fair/poor). Although these were measured slightly differently, categories are comparable across samples. "Percentage more than usual in ELSA, and in Whitehall, the pain score from the SF-36 was dichotomized into low/high pain scores.

Table 2 Multivariable logistic regression analysis for variables predicting DNA consent in Whitehall II $(N=6,870)$

\begin{tabular}{|c|c|c|c|c|}
\hline Variables & $\beta$ (SE) & $P$ & OR & $(95 \% \mathrm{Cl})$ \\
\hline Sex (male vs. female) & $0.354(0.322)$ & 0.271 & 1.425 & $0.759-2.678$ \\
\hline $\begin{array}{l}\text { Ethnicity (white vs. } \\
\text { nonwhite) }\end{array}$ & $1.232(0.382)$ & 0.001 & 3.428 & $1.621-7.251$ \\
\hline Age & $-0.041(0.025)$ & 0.099 & 0.960 & $0.915-1.008$ \\
\hline $\begin{array}{l}\text { Marital status } \\
\text { (married/cohab vs. } \\
\text { single/div/wid) }\end{array}$ & $-0.013(0.354)$ & 0.771 & 0.902 & $0.451-1.804$ \\
\hline $\begin{array}{l}\text { Education } \\
\text { (no vs. other) }\end{array}$ & $-0.627(0.386)$ & 0.104 & 0.534 & $0.251-1.137$ \\
\hline $\begin{array}{l}\text { Wealth (up to } \\
\mathrm{f} 40 \mathrm{k} \text { vs. }>\mathrm{f} 40 \mathrm{k} \text { ) }\end{array}$ & $-0.250(0.425)$ & 0.557 & 0.779 & $0.339-1.792$ \\
\hline $\begin{array}{l}\text { Religious activity } \\
\text { (no vs. yes) }\end{array}$ & $-0.108(0.313)$ & 0.729 & 0.897 & $0.485-1.658$ \\
\hline $\begin{array}{l}\text { Self-reported health } \\
\text { (often vs. sometimes/ } \\
\text { rarely/never) }\end{array}$ & $0.444(0.532)$ & 0.404 & 1.559 & $0.550-4.423$ \\
\hline Chronic pain score & $-0.002(0.007)$ & 0.801 & 0.998 & $0.985-1.012$ \\
\hline $\begin{array}{l}\text { Depression score } \\
\text { GHQ }\end{array}$ & $-0.042(0.074)$ & 0.572 & 0.959 & $0.830-1.108$ \\
\hline $\begin{array}{l}\text { Self-reported control } \\
\text { over life events } \\
\text { (often vs. } \\
\text { sometimes/rarely/ } \\
\text { never) }\end{array}$ & $-0.568(0.670)$ & 0.397 & 0.567 & $0.152-2.107$ \\
\hline
\end{tabular}

$\mathrm{Cl}$, confidence interval; GHQ, General Health Questionnaire; OR, odds ratio. health, and pain were no longer associated with DNA consent in the multivariate analyses.

Corresponding results from the multivariate regression analysis for the ELSA cohort are listed in Table 3, and the results largely matched those from Whitehall II. Among the demographic variables, only ethnic group $(P=0.008)$ was significantly associated with consent. However, with respect to psychological/health variables, perceived control over life events $(P=0.003)$ remained associated with consent.

\section{DISCUSSION}

In two established epidemiological cohort studies in the United Kingdom, the Whitehall II study and the ELSA, consent to DNA collection was more than $98 \%$. We found some evidence that distinct socioeconomic and psychological features characterized the small group of participants who declined DNA collection, supporting the point of Melas et al. ${ }^{8}$ that consenting to DNA collection is unlikely to be simply a matter of time or convenience. Considerable time commitment is involved in participation in epidemiological studies, and consent to blood sampling is usually part of the protocol; therefore, declining DNA collection is likely to be an active process.

Of the factors examined in this study, the strongest predictor of declining DNA collection was coming from an ethnic minority background. This was evident in both samples, and the finding remained significant after adjustment for a number 
Table 3 Multivariable logistic regression analysis for variables predicting DNA consent in $\operatorname{ELSA}(N=6,618)$

\begin{tabular}{|c|c|c|c|}
\hline Variables & $\beta$ (SE) & $P$ & OR $(95 \% \mathrm{Cl})$ \\
\hline Sex (male vs. female) & $-0.432(0.313)$ & 0.168 & $0.649(0.351-1.200)$ \\
\hline Ethnicity (white vs. nonwhite) & $-1.635(0.616)$ & 0.008 & $0.195(0.058-0.652)$ \\
\hline Age & $-0.017(0.015)$ & 0.257 & $0.983(0.955-1.012)$ \\
\hline Marital status (married/cohab vs. single/div/wid) & $0.293(0.342)$ & 0.392 & $1.340(0.686-2.618)$ \\
\hline Education (no vs. other) & $-0.177(0.322)$ & 0.582 & $0.838(0.446-1.573)$ \\
\hline Wealth (lowest quintile vs. other) & $-0.251(0.368)$ & 0.495 & $0.778(0.379-1.600)$ \\
\hline Religious activity (no vs. yes) & $-0.070(0.339)$ & 0.836 & $0.932(0.480-1.810)$ \\
\hline Self-reported health (excellent vs. good/fair/poor) & $0.526(0.558)$ & 0.346 & $1.691(0.567-5.050)$ \\
\hline Often troubled by pain (no vs. yes) & $-0.033(0.308)$ & 0.916 & $0.986(0.529-1.771)$ \\
\hline Depression score CES-D & $-0.121(0.087)$ & 0.163 & $0.886(0.749-1.050)$ \\
\hline Self-reported control over life events (sometimes/rarely/never vs. often) & $-1.262(0.431)$ & 0.003 & $0.283(0.122-0.659)$ \\
\hline
\end{tabular}

CES-D, Centre for Epidemiologic Studies-Depression Scale; Cl, confidence interval; OR, odds ratio.

of socioeconomic and health-related covariates. Five other sociodemographic and psychological factors (being female, involvement in religious activity, lower level of education, poor self-reported health, and more pain) were significant predictors in one sample and in the same direction in the other, but none of these remained an independent predictor in the multivariate regression analysis. However, perceived control over life events (higher) predicted participation in DNA collection only in ELSA, and this effect survived multivariate regression analysis.

Involvement in religious activity seemed to be a significant predictor of declining DNA collection in the univariate analyses, but this association was no longer significant once ethnicity was controlled for in the multivariate analysis; although sample size may have limited our ability to detect small effects. This hints at reasons other than the assumption that DNA has a special status in those who are religious. Familiarity with genetics seems to be an unlikely cause of the finding, as declining was not associated with education. Perceptions about the medical field in general and genetics in particular differ in cultures and range from trust to suspicion, ${ }^{23}$ which may have contributed to higher rates of nonconsent among participants from nonwhite backgrounds. Concepts of autonomy and familial responsibility also differ between western and nonwestern cultures, ${ }^{24}$ which may also have influenced the findings. Because consenting to DNA information was not the primary aim of the study and not studied in detail in the original study, we were unable to investigate reasons for nonparticipation in detail. Future qualitative investigations could provide a more in-depth understanding of the reasons behind declining testing.

The major limitation of the study is the select nature of the study samples. DNA collection was only offered after longstanding participation, and these results may not generalize to samples where DNA sampling is offered from the outset. However, as we investigated key psychosocial and demographic characteristics associated with DNA consent in two different large cohorts, and the outcomes were similar, this lends confidence in the validity of the results. Finally, both cohorts included only older individuals, and Whitehall II is a special cohort from one large employment sector. To obtain a more complete picture, research is needed determining factors affecting DNA consent in the younger population.

In conclusion, our findings support the high consent rates reported previously in studies relating to biobanks., ${ }^{4,7}$ This indicates that DNA sampling is unlikely to result in major biases relative to demographic representativeness, although people from ethnic minority backgrounds were less likely to participate. Reasons for nonparticipation need to be explored in future research. However, differences between the subset of the population unwilling to provide DNA samples and those who consent indicate that if there were greater proportions of decliners, this would create an important source of selection bias.

\section{ACKNOWLEDGMENTS}

This work is supported by Cancer Research UK (C1418/ A10843). The Whitehall II study has been supported by grants from the British Medical Research Council; the British Heart Foundation; the British Health and Safety Executive; the British Department of Health; the National Heart, Lung, and Blood Institute, NIH (grant number: HL36310); and the National Institute on Aging, NIH (grant numbers: AG13196 and AG34454). The English Longitudinal Study of Ageing was developed by a team of researchers based at University College London, the Institute of Fiscal Studies, and the National Centre for Social Research. The data were made available through the UK Data Archive. The funding is provided by the National Institute on Aging in the United States (grants 2RO1AG764401A1 and 2RO1AG017644) and a consortium of UK government departments coordinated by the Office for National Statistics. The developers and funders of ELSA and the Archive do not bear any responsibility for the analyses or interpretations presented here.

\section{DISCLOSURE}

The authors declare no conflict of interest.

\section{REFERENCES}

1. Scheuner MT, Sieverding P, Shekelle PG. Delivery of genomic medicine for common chronic adult diseases: a systematic review. JAMA 2008;299: 1320-1334.

2. Chung WK. Implementation of genetics to personalize medicine. Gend Med 2007:4:248-265 
3. Khoury MJ, Gwinn M, Burke W, Bowen S, Zimmern R. Will genomics widen or help heal the schism between medicine and public health? Am J Prev Med 2007;33:310-317.

4. Goddard KA, Smith KS, Chen C, McMullen C, Johnson C. Biobank recruitment: motivations for nonparticipation. Cell Preserv Technol 2009; 7:119-122.

5. Pulley JM, Brace MM, Bernard GR, Masys DR. Attitudes and perceptions of patients towards methods of establishing a DNA biobank. Cell Tissue Bank 2008;9:55-65

6. Hoeyer K, Olofsson BO, Mjörndal T, Lynöe N. Informed consent and biobanks: a population-based study of attitudes towards tissue donation for genetic research. Scand J Public Health 2004;32:224-229.

7. Johnsson L, Hansson MG, Eriksson S, Helgesson G. Patients' refusal to consent to storage and use of samples in Swedish biobanks: cross sectional study. BMJ 2008;337:a345.

8. Melas PA, Sjöholm LK, Forsner T, et al. Examining the public refusal to consent to DNA biobanking: empirical data from a Swedish populationbased study. J Med Ethics 2010;36:93-98.

9. Galea S, Tracy M. Participation rates in epidemiologic studies. Ann Epidemiol 2007;17:643-653.

10. Ferrie JE, Kivimäki $M$, Singh-Manoux A, et al. Non-response to baseline, non-response to follow-up and mortality in the Whitehall II cohort. Int J Epidemio/ 2009;38:831-837.

11. Scholes S, Taylor R, Cheshire H, Cox K, Lessof C. Retirement, health and relationships of the older population in England: the 2004 English Longitudinal Study of Ageing Technical Report. National Centre for Social Research: London, 2008

12. Marmot M, Banks JA, Blundell R, Lessof C, Nazroo J. Health, Wealth and Lifestyles of the Older Population in England: The 2002 English Longitudinal Study of Ageing. The Institute for Fiscal Studies: London, 2003.
13. Marmot MG, Smith GD, Stansfeld S, et al. Health inequalities among British civil servants: the Whitehall II study. Lancet 1991;337:1387-1393.

14. Banks J, Breeze E, Lessof C, Nazroo J. Retirement, Health and Relationships of the Older Population in England: The 2004 English Longitudinal Study of Ageing (wave 2). The Institute for Fiscal Studies: London, 2006

15. Banks JA, Karlsen S, Oldfield Z. Socio-economic position. In: Marmot M, Banks JA, Blundell R, et al., (eds). Health, Wealth andLlifestyles of the Older Population in England: the 2002 English Longitudinal Study of Ageing. Institute of Fiscal Studies: London, 2003:15.

16. Braveman PA, Cubbin C, Egerter $S$, et al. Socioeconomic status in health research: one size does not fit all. JAMA 2005;294:2879-2888.

17. Shankar A, McMunn A, Steptoe A. Health-related behaviors in older adults relationships with socioeconomic status. Am J Prev Med 2010;38:39-46.

18. McMunn A, Nazroo J, Breeze E. Inequalities in health at older ages: a longitudinal investigation of the onset of illness and survival effects in England. Age Ageing 2009;38:181-187.

19. Ware JE Jr, Sherbourne CD. The MOS 36-item short-form health survey (SF-36). I. Conceptual framework and item selection. Med Care 1992;30:473-483.

20. Goldberg DP. Detecting Psychiatric IIIness by Questionnaire. Oxford University Press: Oxford, UK, 1972.

21. Radloff LS. The CES-D scale. App/ Psych Meas 1977;1:385-401.

22. Hyde $M$, Wiggins $R D$, Higgs $P$, Blane $D B$. A measure of quality of life in early old age: the theory, development and properties of a needs satisfaction model (CASP-19). Aging Ment Health 2003;7:186-194.

23. Suther S, Kiros GE. Barriers to the use of genetic testing: a study of racial and ethnic disparities. Genet Med 2009;11:655-662.

24. Burgess MM. Beyond consent: ethical and social issues in genetic testing. Nat Rev Genet 2001;2:147-151. 